Address for Correspondence: Prof. Lawrence Grouse, MD, PhD Department of Neurology, University of Washington School of Medicine, Rm RR650, Seattle, Washington 981956465, USA.

Email: Igrouse@uw.edu

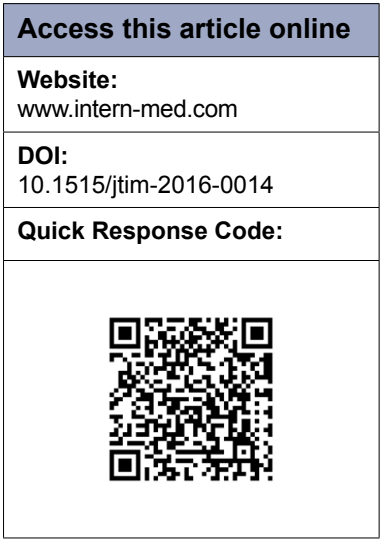

\title{
Galileo in Bethesda: The future of gene editing
}

\author{
Lawrence Grouse ${ }^{1,2}$ \\ 'Executive Director, International COPD Coalition; \\ 2University of Washington School of Medicine, Gig Harbor, Washington, USA
}

In the recent article concerning the political obstacles to human genetic research that have occurred in the United States ${ }^{[1]}$, concern was expressed about the risk of governmental interference in the research of new gene editing and genetic therapy technology that is being developed. In the interim, the US National Academy of Sciences (NAS), National Academy of Medicine (NAM), and National Institutes of Health (NIH) have, in fact, moved to impede this research in various ways. The most concerning development, following a meeting on gene editing research convened by NAS and NAM, was the release of statements including the demand for a moratorium on proceeding with important aspects of gene editing research.

The NIH director, Dr. Francis Collins, announced that NIH will not fund research on human embryos. Further, NIH leaders have published an article concerning their proposed revisions to the "Common Rule," an informal name for the government regulations governing the ethical conduct of research involving humans. ${ }^{[2]} \mathrm{NIH}$ would require consent for the use of all human biospecimens in research and would extend the Common Rule regulations to unregulated privately-funded clinical trials at institutions funded for human subject research. The NAS consensus statement advocated a moratorium on human embryo research that might result in pregnancy and inheritance of edited genes.

The NAS is usually referred to as a quasigovernmental organization because of the role it plays for the US government, but it is not a government agency. However, the NAS/NAM meeting and the research study on gene editing being carried out by NAS staff and consultants is in large part funded by the US government through the US Food and Drug Administration. These concerted activities strongly suggest that the US government is continuing its policy of interference with scientific inquiry that has been so damaging to the progress of genomic medicine. The acrimonious political controversy involving US religious factions opposing women's reproductive freedom ${ }^{[1]}$ appears to have forced US government scientific leaders to attempt to suspend the principles of medical research.

The specific concerns for these organizations' opposition to various aspects of gene editing is not entirely clear based on information currently available; however, an article by Jasanoff et al. ${ }^{[3]}$ posted on the US National Academy of Science's website as part of the promotion for the recent NAS/ NAM International Summit meeting on gene editing contains arguments that support the US government's position on the regulation of genome science research and the moratorium it proposes. The article was also published in the NAS's Issues in Science and Technology publication, and even though gene editing is a controversial subject, the NAS did not post or publish any articles with contrary opinions. The consensus statement issued by NAS following the International Summit meeting also provided no rebuttal or second opinions. Because alternative opinions, which were excluded from the NAS coverage, should be heard, this commentary critiques the Jasanoff et al. article and the demand for a moratorium on gene editing. 
The proper model for considering the ethical, scientific path for translational research on gene editing should be developed by knowledgeable scientists and other experts in a process like the 1975 Asilomar Conference on Recombinant DNA Research, led by Paul Berg. The conference identified potential risks and decided on steps to prevent them. The practical guidelines agreed upon at the 1975 Asilomar meeting have been eminently successful in launching quality rDNA scientific research while avoiding the promulgation of dangerous genetically modified organisms or their products. To my knowledge, there have been no instances of any biologically significant problems associated with the development and implementation of this recombinant DNA technology. If the future of translational research with gene editing has similar safe and beneficial results, the people of the world will be well served.

The key to the success of the Asilomar summit meeting was that it was not a governmental meeting that would have embroiled recombinant DNA research in politics and bureaucracy. It was organized and attended by a respected international group of scientists and policy experts. The conclusions of the meeting in terms of practical scientific procedures to implement were actionable, effective, and ultimately successful. They were not legal regulations, and the conclusions were not binding on scientists, research institutions, or governments.

The successful progress in gene editing for genetic diseases is of great public health importance. Geneticists estimate that about $10 \%$ of all individuals suffer from deleterious gene mutations. ${ }^{[3]}$ This represents more than 700 million people worldwide. Other genetic abnormalities are responsible for many cases of cancer, heart disease, and other categories of disease. Genes that carry predisposition to diseases ${ }^{[4]}$ are also common.

In terms of the total number of global disability-associated life years (DALYs), more than $20 \%$ of humanity's disabilities result from mental illness and neurologic disease, both of which can lead to tragic neurodevelopmental diseases such as schizophrenia, epilepsy, autism, bipolar disorder, and major depression. Recent findings reveal that many of these patients have mutations that are often associated with genetic copy number variants $(\mathrm{CNVs})$ that are responsible for their disease. ${ }^{[5]}$ More than $10 \%$ of all individuals may suffer from these diseases during their lives. These facts indicate that a major fraction of people worldwide-more than one billion people- have genetically related diseases causing disability and death. The need for effective gene editing, gene repair, gene replacement, and other gene therapy, which offer the possibility of prevention and cure of these diseases, is enormous. For each year that the development of prevention and cures of genetic diseases are delayed, it can be estimated that more than 50 million people will die unnecessarily. Compare this with the yearly global cancer deaths of 8.2 million.

Medical science is only at the starting point in terms of being able to address this genetic disease burden therapeutically. That is why promising new genomic approaches for genetic disease diagnosis ${ }^{[6]}$ and therapy ${ }^{[7]}$ are so important and why their development should be fostered and not hamstrung with unsolvable bureaucratic, political, and religious controversies that would halt progress in achieving effective treatment. The involvement of governments and quasigovernmental organizations in discussing future research for genetic diseases as advocated in the Jasanoff et al. article can only insert into the process extraneous issues totally unrelated to patients' medical needs, scientific and public safety, and the appropriate conduct of medical research.

The authors of the article include two medical ethicists and a faculty member in a school of government. The absence of the perspective of a bench scientist with research experience in genome science or a physician geneticist with patients' interests as their major concern leads to a rather distorted view of how genome research should proceed.

Dr. Berg was criticized by the authors for saying that the Asilomar meeting paved the way for "geneticists to push research to its limits without endangering public health." Clearly, Dr. Berg meant that scientists should do their best to understand the genetics and deliver the most valuable results of their work while ensuring that it would not become a risk to the public. However, the authors imply that Dr. Berg's remark meant that he intended for scientists to push the scope of their research so that it would cause public danger and harm. This is the opposite of what he says.

The authors correctly argue that each member of our species owns their own human genome, but they seem to imply that this means that every human should participate in deciding what medical and scientific procedures in treating genetic diseases should be undertaken. This is not possible and not desirable. They criticize the Asilomar process because they claim that it caused anger and disruption by people who opposed the development of genetically modified crops. Their opposition was not the result of the Asilomar process. In a democracy where people have the right to different opinions, one can be sure that any new scientific procedure will have both adherents and detractors. For detractors and those who oppose science in general, any and all prejudices would be valid reasons to limit scientific inquiry and access to new scientific procedures; however, this is not in the interest of society and it should not be advocated by US governmental science organizations. 
As the level of scientific knowledge concerning genetics and genome science among the public is low, it would certainly be useful for the US government to provide factual educational materials to the public concerning genetic disease and therapy. Also, substantive input about the impact of new genetic procedures should be welcomed from all sources, but irrational and uninformed opposition to safe and effective medical procedures should not be allowed to prevent patients from receiving life-saving care. Science cannot control or alter the social-economicpolitical consequences of scientific advances, and it should not be expected to do so.

The authors put forward several arguments that must be interpreted as reasons for not developing cures for genetic diseases.

1.They argue that developing cures for genetic diseases could have the result of putting money-raising charities for these diseases out of business. They further argue that people who already have these genetic diseases may feel stigma in society because they should have had their conditions prevented or cured. These do not seem to be persuasive reasons to deprive all future patients from effective care or to prevent the eradication of these diseases.

2. The authors criticize the production of recombinant insulin because "...insulin remains an expensive drug. Its cost keeps it out of reach for some Americans, with disastrous implications for their health." Apparently they would have opposed production of recombinant insulin unless all people could have access to it. They ignore the fact that different societies have different social and economic systems. Neither the production of recombinant insulin nor the development of cures for genetic diseases can change these systems. In the US drug prices are much higher than in any other country, but this fact is not the result of the production of recombinant human insulin, a medical advance that has greatly benefited diabetes care.

3. The authors are concerned about research on treating genetic diseases because it may lead to commercial therapies whose process of development may upset the public: "Specific public worries include the ethics of transnational clinical trials, access to essential medicines, and intellectual property rights that discriminate against generic drugs produced in developing countries." Clearly the authors' interest in government regulation and economics takes precedence over their concern for patient welfare and improved scientific knowledge.
4. The authors are most concerned about how government intervention in the care of genetic disease might evolve. They discuss " .... when money should be directed from high-cost individualized treatment to lower-cost public health interventions." It is hard to accept the notion that governments can withhold life-saving care for individuals with genetic diseases and use the money for public health care just because curing genetic diseases costs more.

5. The authors' expectation appears to be that government will control what scientific advances are made and have them appear in a manner that pleases all the elements of society. "The challenge for democracy and governance is to confront the unscripted future presented by technological advances and guide it in ways that synchronize with democratically articulated visions of the good." This is a pipe dream.

The inevitability of germ line genetic editing is clear. As Craig Venter said, ${ }^{[3]}$ "The question is when, not if." Chinese scientists and Chinese companies are actively pursuing both human genetic editing as well as alteration of the genomes of numerous types of domesticated animals for commercial use. Oncologists from the UK, America, and other developed countries are using genetic editing to provide treatments for various malignancies. Other creative uses of gene editing systems are rapidly being deployed. This is as it should be.

Different countries have varying laws and agencies regulating drugs, devices, and medical procedures. Gene editing technology will have to satisfy these processes before it can be licensed. There is no need for moratoriums while governments discover once again that there are always divided opinions on new technologies. There is no need for governments or religious authorities to regulate what science will do and discover. Galileo's incarceration for describing heliocentricity should not be repeated in modern times.

Introducing political and religious control of the scientific process is counter-productive. In the United States, drug company payments to politicians control congressional policies toward medicines and lead to favorable commercial opportunities for pharmaceuticals and financial hardships for patients. US religious groups' political influence supports the adoption of their anti-science and anti-abortion policies by the US government. US scientific organizations are funded and controlled by the US government. Is this the sort of government whose policies toward science should be followed throughout the world?

None of the documents or statements of the NAS or $\mathrm{NIH}$ concerning gene editing addresses the real reason why the US government and many other governments 
oppose the embryo and fetal research that is necessary to achieve cures of genetic diseases. That reason is the opposition of conservative religious groups, many of which believe that the moment an oocyte is fertilized by a sperm it has a soul and because of this the embryo may not be harmed. The attacks and threats that the US government would be closed unless the funding of the reproductive health organization Planned Parenthood was terminated demonstrate the zealotry of this large US constituency. The US government should maintain the separation of church and state. Allowing government to halt the scientific process of developing cures of genetic diseases on behalf of political expediency is a tragedy for these patients. Important research questions about gene editing can be addressed and answered by scientific experts as part of the scientific process. It should not be interrupted by behind the scene political censorship.

Medical research should follow its established rules of safety, scientific inquiry, efficacy, advocacy for health, and service to patients. Governmental interference in scientific research due to political, commercial, and religious influence has greatly impaired a generation of researchers by restricting research using human tissue. ${ }^{[1]}$ This should not be allowed to continue. More than a billion sufferers from genetic diseases are forced to endure this political charade.

\section{Conflict of Interest}

None declared.

\section{REFERENCES}

1. Grouse L. Translational Genetic Research of Complex Diseases. J Transl Intern Med 2015; 3: 137-43.

2. Hudson KL, Collins FS. Bringing the Common Rule into the $21^{\text {st }}$ Century. N Engl J Med 2015;373:2293-6.

3. Jasanoff S, Hurlbut JB, Saha K. CRISPR Democracy: Gene Editing and the Need for Inclusive Deliberation. Available at: http://issues.org/32-1/ crispr-democracy-gene-editing-and-the-need-for-inclusive-deliberation/. Accessed on January 26, 2016.

4. Zhang J, Walsh MF, Downing J, Gruber TA, Easton J, Hedges D, et al. Germline Mutation in Predisposition Genes in Pediatric Cancer. N Engl J Med 2015; 373:2336-46.

5. Coe BP, Girirajan S, Eichler EE. The Genetic Variability and Commonality of Neurodevelopmental Disease. Am J Med Genet C Semin Med Genet 2012;160C:118-29.

6. Stessman HA, Bernier R, Eichler E. A Genotype-first approach to defining the subtypes of a complex disease. Cell 2014;156:872-7.

7. Claussnitzer M, Dankel SN, Kim KH, Quon G, Meuleman W, Haugen $\mathrm{C}$, et al. FTO Obesity Variant Circuitry and Adipocyte Browning in Humans. N Engl J Med 2015;373:895-907.

How to cite this article: Grouse L. Galileo in Bethesda: The future of gene editing. J TransI Intern Med 2016; 4: 143-46. 